\title{
OS DESAFIOS AO TORNAR-SE PROFESSOR/A: UMA ANÁLISE DA PROFISSIONALIDADE DOCENTE NA EDUCAÇÃO INFANTIL
}

\author{
LOS RETOS DE SER PROFESOR: ANALISIS DE LA PROFESIONALIDAD DOCENTE \\ EN EDUCACIÓN INFANTIL
}
THE CHALLENGES WHEN BECOMING A TEACHER: AN ANAL YSIS OF THE TEACHER PROFESSIONALITY IN EARLY CHILDHOOD EDUCATION

\author{
Tânia Rodrigues PALHANO ${ }^{1}$ \\ Lindinalva de Alcântara CORREIA ${ }^{2}$ \\ Elidiana Oliveira das NEVES ${ }^{3}$
}

RESUMO: O texto consiste em discutir, a partir de uma pesquisa com professores/as da Educação Infantil, os desafios ao tornar-se professor/a, vislumbrando a profissionalidade docente. Assim, essa investigação examinou fatores sociodemográficos relacionados a faixa etária, vínculo empregatício e formação. Foi realizada com as professoras que atuam nessa etapa da educação, em dois Centros de Referência em Educação Infantil-CREI, a partir de entrevista semiestruturada. Contou com a participação de 20 docentes da Rede Pública Municipal de Ensino de João Pessoa - Paraíba. Na análise dos dados obtidos, utilizamos a análise de conteúdo, com a técnica da análise temática. Os resultados evidenciaram que os/as docentes apresentam satisfação com a formação profissional inicial, e que um dos maiores desafios após a graduação é retornar à academia para estudar e manter-se ativo num processo de formação permanente. Com os resultados, pode-se pensar na ampliação das vagas ofertadas nos cursos de pós-graduação na área da educação, bem como o incentivo aos estudantes egressos da graduação, no sentido da sua permanência enquanto profissionais pesquisadores/as.

PALAVRAS-CHAVE: Profissionalidade docente. Educação infantil. Profissão docente.

RESUMEN: El texto pretende discutir, a partir de una investigación con profesores de Educación Infantil, los retos para llegar a ser profesor, apuntando a la profesionalidad docente. Así, esta investigación examinó los factores sociodemográficos relacionados con el grupo de edad, el vínculo laboral y la educación. Se realizó con docentes que trabajan en esta etapa educativa, en dos Centros de Referencia de Educación Infantil-CREI, a través de entrevistas semiestructuradas. Contó con la participación de 20 profesores de la Red Municipal de Educación Pública de João Pessoa - Paraíba. En el análisis de los datos

\footnotetext{
${ }^{1}$ Universidade Federal da Paraíba (UBPB), João Pessoa - PB - Brasil. Professora de Filosofia da Educação do Centro de Educação da UFPB e Docente do Programa de Pós-graduação em Educação (PPGE). Pós-Doutorado em Educação (UNICAMP) e Doutorado em Educação (UFPB). ORCID: https://orcid.org/0000-0002-8393-6060. E-mail: taniarpalhano@gmail.com

${ }^{2}$ Universidade Federal da Paraíba (UBPB), João Pessoa - PB - Brasil. Mestranda no Programa de PósGraduação em Educação. ORCID: https://orcid.org/0000-0002-8393-6060. $\quad$ E-mail: lindinalvaalcantara@gmail.com

${ }^{3}$ Universidade Federal da Paraíba (UBPB), João Pessoa - PB - Brasil. Mestranda no Programa de PósGraduação em Educação. ORCID: https://orcid.org/0000-0001-6341-7661. E-mail: elidiana.bn@gmail.com
} 
obtenidos, se utilizó el análisis de contenido, con la técnica del análisis temático. Los resultados mostraron que los profesores están satisfechos con la formación profesional inicial, y que uno de los mayores retos después de la graduación es volver a la academia para estudiar y permanecer activos en un proceso de formación continua. Con los resultados, se puede pensar en la ampliación de las vacantes ofrecidas en los cursos de postgrado en el área de educación, así como en el estímulo a los estudiantes de postgrado, en el sentido de su permanencia como investigadores profesionales.

PALABRAS CLAVE: Profesionalidad docente. Educación infantil. Profesión docente.

ABSTRACT: The text is to discuss, based on a research with teachers of Early Childhood Education, the challenges of becoming a teacher, aiming at the teaching professionalism. Thus, this investigation examined sociodemographic factors related to age, employment status, and education. It was carried out with teachers who work in this stage of education, in two Reference Centers for Early Childhood Education (Centros de Referência em Educação Infantil-CREI), through semi-structured interviews. It counted with the participation of 20 teachers from the Municipal Public Education Network of João Pessoa - Paraiba. In the analysis of the data obtained, we used content analysis, with the thematic analysis technique. The results showed that the teachers are satisfied with their initial professional formation, and that one of the biggest challenges after graduation is to return to the academy to study and keep active in a process of permanent formation. With the results, it is possible to think about the expansion of vacancies offered in graduate courses in the area of education, as well as the encouragement to graduate students, in the sense of their permanence as professional researchers.

KEYWORDS: Teaching professionality. Child education. Teaching profession.

\section{Introdução}

Na contemporaneidade da educação os desafios ao tornar-se professor/a para atuar na Educação Infantil perpassa pela constituição da profissionalidade docente, tendo em vista as peculiaridades dessa etapa da educação. Além disso, a criança de zero a cinco anos de idade necessita de um espaço educativo diferenciado, que realmente atenda suas necessidades em espaços que perceba a criança como "sujeito histórico e de direitos que, nas interações, relações e práticas cotidianas que vivencia, constrói sua identidade pessoal e coletiva" (BRASIL, 2010). Do contrário quando essas necessidades não são atendidas, é negado a criança o direito de produzir cultura, a partir das brincadeiras, imaginação, observação, experimentação, ou seja, de construir sentidos sobre a natureza e a sociedade, na perspectiva de atender às especificidades do seu desenvolvimento global (psicológico, físico, intelectual e social).

RPGE- Revista on line de Política e Gestão Educacional, Araraquara, v. 25, n. 3, p. 2393-2407, set./dez. 2021. e-ISSN: 1519-9029 
Essa constatação exige que a formação profissional do docente seja construída ao longo da sua trajetória de vida, com saberes provenientes do conhecimento de mundo, da realidade social e cultural, visto que precisa ser resultante de um processo contínuo que visa gerar transformações nas concepções e consequentemente nas práticas educativas.

Sendo assim, para melhor entendimento, este artigo está dividido, além das palavras introdutórias que descreve a contextualização da investigação, o problema, os objetivos, os processos metodológicos, a fundamentação teórica que esclarece sobre a profissionalidade docente de professores no contexto da primeira etapa da Educação Básica na Rede Pública Municipal de Ensino de João Pessoa-Paraíba - RPMEJP-PB , e por fim, as considerações finais.

Nessa direção, esta pesquisa se justifica pela necessidade de aprofundamento teórico que balize nossas reflexões acerca dos desafios ao tornar-se professor/a, a partir de uma análise da profissionalidade docente na Educação Infantil, no que concerne às realidades de formação e suas implicações na atuação docente com a criança de 0 a 5 anos de idade, bem como pela emergência, enquanto docentes, em contribuir junto a educação para discussão acerca desse tema.

Diante do exposto, este estudo emerge de algumas inquietações geradas ao longo da trajetória acadêmica e profissional, marcada pela sala de aula há algum tempo, bem como da experiência de professora formadora na (RPMEJP-PB), que acompanha a ação educativa nos Centros de Referências em Educação Infantil - CREIs. A prática docente teve início desde a década de 1980 como professora da educação básica em instituições de ensino públicas e privadas no Estado da Paraíba. Ao atuar nessa etapa da educação foi possível perceber como acontece a atuação docente com as diferentes faixas etárias.

O desenvolvimento da pesquisa instigou-nos a compreender a problemática presente no universo dessa etapa da educação, no sentido de que poderia colaborar na perspectiva de evitar a fragilidade da profissão docente e contribuir com o processo da profissionalidade docente, bem como suscitaram outros questionamentos referentes aos desafios de tornar-se professor/a para atuar nesse campo educacional. Principalmente diante desse contexto de pandemia gerado pelo vírus COVID-19, que ocasionou sérias mudanças no sistema educativo dos países, assim como as transformações curriculares que essa etapa da educação vem passando, somados ao fato em que somos atravessados por uma mudança no curso de formação inicial docente (Pedagogia), que prioriza o fazer pedagógico técnico em detrimento do conhecimento científico, conforme posto na Base Nacional Comum para a Formação Inicial de Professores da Educação Básica - BNC-Formação - RESOLUÇÃO CNE/CP N ${ }^{\circ} 2$, DE 20 DE DEZEMBRO DE 2019 (BRASIL, 2019). 
Durante o período da docência na Educação Infantil, observamos que a maior parte dos/as docentes apresentavam fragilidades em sua atuação, quer seja pela falta de formação adequada ou por lacunas deixadas na sua formação inicial. Outra questão está relacionada à especificidade do trabalho educativo com a criança de 0 a 5 anos de idade, em que as práticas pedagógicas desenvolvidas tendem a ser realizadas como preparação para a fase seguinte, com base em cobrir pontilhados, copiar e repetir, sem considerar que os eixos estruturantes do trabalho pedagógico nessa etapa da educação são as interações e brincadeiras (BRASIL, 2017).

Embora a Secretaria de Educação e Cultura - SEDEC, do Município de João Pessoa, busque protagonizar a formação continuada durante o ano letivo, com intuito de alcançar os objetivos propostos no currículo da Educação Infantil, a Base Nacional Comum CurricularBNCC (BRASIL, 2017), algumas indagações nos inquietaram, como: Quais os desafios ao torna-se professor/a na Educação Infantil? Como adquirir a profissinalidade docente? Qual a concepção do docente em relação à sua profissionalidade?

No entanto, dialogando com órgãos responsáveis pelo processo formativo dos/as professores/as, essencialmente da formação continuada, foi possível perceber a importância dessa prática para os/as professores/as, mas esse trabalho de formação apresenta- se de forma fragilizada, principalmente nesse contexto de pandemia gerada pelo vírus COVID-19 que estamos vivenciando, em que os docentes tiveram de se adaptar as novas formas de desenvolver sua profissão, o que torna o trabalho formativo fragilizado, devido a necessidade do/a docente em se dividir no tripé: trabalho doméstico, função docente, e formação, no espaço do seu lar, além da problemática apresentada, no que se refere a falta de internet, dentre outras problemáticas advindas desse período de pandemia, como questões, econômicas, tecnológicas e sociais.

Por outro lado, é necessário lembrar que a formação do professor vai além da aprendizagem de técnicas e metodologias, requer um envolvimento maior com o desenvolvimento da criança, do currículo, e a capacidade de solucionar problemas relacionados ao contexto da escola ou do CREI. "Não podemos afirmar que o desenvolvimento profissional do professor deve-se unicamente ao desenvolvimento pedagógico" (IMBERNÓN, 2011, p. 45).

Com base no exposto, esta pesquisa parte de um olhar diferenciado da construção da profissionalidade docente como um processo colaborativo, participativo e dinâmico, na relação teoria e prática. Frente a esse contexto, o objetivo geral dessa investigação foi Compreender os desafios de tornar-se professor/a para atuar na Educação Infantil. Os 
objetivos específicos: Reconhecer a profissionalidade docente e Identificar a concepção docente acerca da sua profissionalidade.

As inquietações e objetivos apresentados consideram que a criança pequena necessita de um profissional qualificado, que tenha noção dos conceitos de infâncias e Educação Infantil, que segundo Sarmento (2004), uma infância historicamente construída que apresenta uma pluralização dos modos de ser criança. Assim como Barbosa (2011), uma Educação Infantil que surgiu em um contexto de intensa mobilização de setores da sociedade civil, reconhecida num processo histórico, cultural, com a construção de marcos legais relacionados aos direitos da criança, como "o atendimento em creches e pré-escolas, direito social das crianças que se afirmar na Constituição de 1988, bem como o reconhecimento da Educação Infantil como dever do Estado com a Educação (BRASIL, 1988).

Diante desse contexto, são conhecimentos bem necessários aos docentes que atuam nessa etapa da educação. Assim, esta investigação tem a pretensão de contribuir para o debate acerca da profissionalidade de professores/as da primeira etapa da Educação Básica, sendo necessário lembrar que a formação do professor vai além da aprendizagem de técnicas e metodologias, requer um envolvimento maior com o desenvolvimento da criança, do currículo, e a capacidade de solucionar problemas relacionados ao contexto da escola ou do CREI. "Não podemos afirmar que o desenvolvimento profissional do professor deve-se unicamente ao desenvolvimento pedagógico" (IMBERNÓN, 2011, p. 45).

Vale registrar que a construção da profissionalidade é uma tendência dos últimos anos e busca garantir ao professor em exercício de sua profissão meios de estar se atualizando, a partir de uma postura pesquisadora atentando para as mudanças pedagógicas, sociais, ambientais, econômicas, culturais e tecnológicas. Não há formação definitiva, mas há um processo de constante reflexão, sendo o diálogo e a pesquisa científica principais ferramentas para a formação permanente do/a docente.

A princípio da investigação utilizamos autores como Imbernón (2011) que aponta "a necessária redefinição da docência como profíssão" (IMBERNÓN, 2011, p. 11), alertando para a transformação na formação inicial e permanente do/a docente. Assim como Nóvoa (1995) que alerta sobre a formação docente e profissional, e nos mostra a construção da identidade docente, bem como Ramalho, Nuñez e Guathier (2004) que trata de formar o professor e profissionalizar o ensino, com base nas perspectivas e desafios, dentre outros teóricos que desenvolvem estudos e pesquisas referentes a profissionalidade docente e à questão de tornar-se professor/a, bem como os documentos oficiais e a legislação que trata da profissionalidade nessa etapa da educação. 
Em face dessa discussão, na atual situação da formação docente, raramente são disponibilizados aos profissionais espaços de discussões para a construção da profissionalidade. Isso se justifica pelo fato das secretarias de educação geralmente deixar em segundo plano a oferta de formação continuada para os/as docentes dessa etapa da educação, ou a pouca valorização desse profissional em efetivar a busca por essa formação de forma autônoma, bem como raramente os Institutos de Educação Superiores facilitam o ingresso do docente em cursos de pós-graduação, evidenciando obstáculos quer seja pela oferta de vagas/matrículas, valor das inscrições ou mensalidades, assim como a qualidade do curso ofertado.

Diante desse contexto, na perspectiva do incentivo e acesso dos professores/as que atuam nessa etapa da educação, faz-se necessária uma reflexão na ação e sobre a ação, vinculada ao discurso teórico, tendo como pano de fundo a postura pedagógica docente que reconhece a essência de ser professor/a, que percebe a possibilidade de transformar a sua prática. A reflexão é aqui entendida como possibilidade de olhar a prática de forma diferenciada, perceber na profissionalidade as possibilidades de mudança.

Nessa direção, observa-se que os/as docentes tem buscado espaços formativos na tentativa de redimensionar sua prática pedagógica. Entretanto, vale salientar que a profissão docente se constitui a partir de saberes estruturantes. Desse modo, espera-se que na construção da profissionalidade dos/as professores/as sejam contemplados, refletidos e treinados, o fazer pedagógico. Essa é a razão que repousa por trás desta problemática. A partir das questões evidenciadas, a profissionalidade precisa ir além dos limites e as exigências atuais, e não pode ser vista apenas como um processo de conhecimento, que possibilita a mudança de experiência e inovação, ou apenas reflexão do professor/a sobre sua prática, mas como a contínua reconstrução da identidade profissional e pessoal do professor/a.

\section{Aspectos conceituais sobre profissionalidade docente como ciclo de vida profissional}

No cenário brasileiro, a profissionalidade toma impulso, devido sua importância e implicações na prática pedagógica. Segundo o artigo 62 da LDB de 1996 (BRASIL, 1996) para atuar na primeira etapa da Educação Básica, o docente deve possuir o curso de Pedagogia ou formação em nível superior em qualquer licenciatura e especialização na Educação Infantil ou antigo pedagógico/magistério mais o curso de graduação, sendo que algo mais é necessário, no sentido de que este tenha um amplo conhecimento sobre a criança pequena e 
suas especificidades, na falta compromete-se a qualidade do trabalho a ser desenvolvido nessa etapa da educação.

Por outro lado, o ingresso do/a professor/a na primeira etapa da Educação Básica darse por meio de contrato de prestação de serviço, geralmente, os municípios paraibanos não realizam concurso público para essa etapa da educação, deixando o preenchimento das vagas, a cargo dos vereadores, que preenchem esse campo profissional com eleitores que contribuíram para elegê-lo. Essa realidade requer uma formação continuada mais efetiva para a questão de tornar-se professor construindo a profissionalidade. A esse respeito Kramer (2006) destaca que "formar professores para lidar com crianças pequenas é uma tarefa nova na história da escola brasileira e, para muitos, desconhecida" (KRAMER, 2006, p. 804).

Nessa direção, levando em consideração a ampliação de matrícula na Educação Infantil resultante de políticas de diversificação e flexibilização institucional, se faz necessário que as Secretarias de Educação garantam um ambiente pedagógico favorável à criança valorizando seu desenvolvimento integral, com vistas à promoção da aprendizagem assegurando a garantia de direitos mencionados na Constituição Federal de 1988 (BRASIL, 1988), na LDBEN, Lei no 9.394/96, que asseguram a Educação Infantil como dever de Estado e reafirmam como um direito público subjetivo. Estabelece como $1^{\mathrm{a}}$ etapa da Educação Básica (BRASIL, 1996), nas Diretrizes Curriculares Nacionais para a Educação Infantil (BRASIL, 2010), dentre outros documentos que regem sobre essa etapa da educação.

Destaca-se que diversos estudos convergem para o reconhecimento da necessidade de se compreender melhor como promover a profissionalidade nos novos cenários institucionais, tendo em vista que um melhor entendimento sobre quais fatores contribuem para o tronar-se professor/a pode trazer diversas contribuições para o desenvolvimento dessa etapa da educação. De acordo com Imbernón $(2011$, p. 7):

Parece necessário que toda instituição educativa deve mudar radicalmente,
tornando-se algo realmente diferente, apropriado às enormes mudanças que
sacudiram o último quartel do século XX. Em suma a profissão docente deve
abandonar a concepção predominante no século XIX de mera transmissão do
conhecimento acadêmico, de onde de fato provém, e que se tornou
inteiramente absoleta para a educação dos futuros cidadãos em uma
sociedade democrática: plural, participativa, solidária, integradora.

A profissionalidade docente é um processo composto por três vertentes distintas e indissociáveis, a primeira centrada na criança, o qual deve ser proporcionado que se desenvolva de forma global, isso demanda espaço, tempo e esforço, a segunda centrada nas Instituições de Ensino, que devem proporcionar os meios e recursos para a promoção da 
aprendizagem como processo ativo e participativo e a terceira com foco no empenho, iniciativa e dedicação do docente de se manter numa constante formação.

Complementando o assunto, Imbernón (2011) enfatiza que a instituição educativa precisa que outras instâncias sociais se envolvem e a ajudam no processo de educar por se tratar de uma variável que envolve três perspectivas - a da Instituição de Ensino, com suas metodologias e recursos, a da criança, que inclui capacidades, cognição e interações, e o docente que se constitui em um fator-chave para a promoção da aprendizagem e consequente melhoria na qualidade da educação.

Neste direcionamento, diversos pesquisadores discorrem que a profissionalidade docente será legítima quando contribuir para o desenvolvimento profissional do professor no âmbito do trabalho e de melhoria das aprendizagens profissionais (RAMALHO; NUÑEZ; GAUTHIER, 2004; IMBERNÓN, 2011).

Assim, além de uma boa infraestrutura, e processos didáticos fornecidos pelas unidades de Educação Infantil, se faz necessário auferir se as experiências vivenciadas no ambiente educativo estão promovendo sentimento de satisfação e desenvolvimento das crianças. Fortalecendo esta ideia, Freire (2013, p. 84) relata que:

[...] antes de qualquer tentativa de discussão de técnica, de materiais e de métodos para uma aula, é preciso que o professor/a se ache repousado no saber de que a pedra fundamental é a curiosidade do ser humano. É ela que me faz perguntar, conhecer, atuar, mais perguntar, reconhecer.

$\mathrm{Na}$ Educação Infantil, a base que sustenta as aprendizagens é a relação afetiva entre o/a docente e a criança. Assim, é preciso aproveitar todas as situações de interação entre a criança e o/a professor/a para motivá-la a relacionar-se, a investigar, a perguntar, a buscar soluções. É necessário facilitar contextos ricos que permitam à criança de ficar diante de novas experiências que lhe sejam interessantes e nas quais possam experimentar, manipular, observar, etc. A boa relação entre criança e docente é aquela que se estabelece através de situações de comunicação real, que permitem o educando dar sentido a suas novas aprendizagens.

Nesse sentido, Kohan (2008, p. 21), “a prática da filosofia tem implicações educacionais na medida em que contribui para formar pessoas dispostas para questionar os valores e as ideias que formam suas vidas e as vidas dos seus semelhantes". Desse modo, é importante o conhecimento docente ser valorizado nos processos de formação de professores, a partir de sua atuação profissional. De acordo com Nóvoa, especialista internacional da formação acadêmica de professores/as sugere transformação na formação docente. Nesse 
sentido, Gatti et al. (2013, p. 17), menciona:

As propostas de Nóvoa e suas justificativas podem ser assim sintetizadas: da mesma forma que os médicos são formados por médicos e os engenheiros por engenheiros, por exemplo, os professores precisam ser formados por professores, ou seja, a profissão, por seus representantes, deve ter um papel relevante na formação dos novos profissionais.

Diante desse contexto, as situações problemáticas aparecem e obrigam ao profissional da educação a elaborar e construir o sentido de cada situação. Por isso a formação deve aproximar-se da prática educativa. A esse respeito Imbernón (2011, p. 121), aponta:

O contato da formação com a prática educativa faz com que o conhecimento profissional se enriqueça com outros âmbitos: moral e ético, além de permitir que se fomente a análise e a reflexão sobre a prática educativa, tentando uma recomposição deliberativa dos esquemas, concepções e crenças que o conhecimento pedagógico tem sobre o ensino e a aprendizagem. Permitiria trabalharem benefício do professor e da educação da humanidade.

Partindo dessas considerações, este artigo propõe aprofundar o tema profissionalidade docente apresentando a atuação do/a professor/a como um desafio para a questão de tornar-se professor/a. Além disto, examina, através de análise estatística, fatores que podem afetar a atuação nessa etapa da educação, como vínculo empregatício, faixa de idade e conhecimento da constituição da profisssionalidade.

Para que os objetivos deste estudo fossem alcançados foi desenvolvida entrevista semiestruturada em formato eletrônico, o qual obteve 20 respostas válidas e foi validado, através da tabulação dos gráficos. Além desta análise, os dados obtidos foram dispostos as estatísticas descritivas e análise de variância.

\section{Procedimentos metodológicos}

Adotamos o enfoque fenomenológico para compreendermos os desafios ao tornar-se professor, com vistas a profissionalidade docente na Educação Infantil, na busca de compreender como os sujeitos deixam suas impressões, sentimentos, percepções e experiências sobre esse objeto. "O método fenomenológico enfoca fenômenos subjetivos na crença de que verdades essenciais acerca da realidade são baseadas na experiência vivida" (MOREIRA, 2002, p. 108).

Nessa direção, optamos por uma abordagem de natureza qualitativa, que "foca no ser humano enquanto agente, e cuja visão de mundo é o que realmente interessa" (MOREIRA, 
2002, p. 58). Desse modo, questionamos o fenômeno colocando em suspensão as crenças e as pressuposições que circundam esse objeto no contexto dessa etapa da educação. Em seguida, a partir da análise temática, apresentamos a essência deste fenômeno, com elementos pessoais e culturais, tendo em vista que nessa fase, reproduzimos as experiências vividas pelos sujeitos entrevistados.

Nesse contexto, em harmonia com o foco principal desta pesquisa, foi utilizada uma entrevista semiestruturada de forma virtual, por meio do aparelho celular e realizada no período de 10 de julho a 04 de agosto de 2021. "Na entrevista semiestruturada há maior liberdade do entrevistador, levantar outras questões, dependendo das respostas dos entrevistados" (MOREIRA, 2002, p. 55). Esse instrumento de obtenção de informações favorece a descrição, a explicação e a compreensão do fenômeno estudado, e foi escolhido por facilitar maior informação e melhor contato com os/as professores/as. Desse modo desenvolve-se numa abordagem qualitativa, pois permite maior envolvimento entre o pesquisador e seu objeto de estudo. De acordo com Minayo (1994), a pesquisa qualitativa pode ser como estudo detalhado de determinado fenômeno social que busca informações para explicar.

Em relação a análise dos dados optamos pela análise temática, que consiste em uma das modalidades da análise de conteúdo, conforme Bardin (1977, p. 105), a análise temática objetiva desvendar o que está por trás das palavras sobre as quais se debruça, e assim “descobrir os 'núcleos de sentido' que compõem a comunicação e cuja presença ou frequência de aparição podem significar alguma coisa para o objetivo analítico escolhido.

Nessa direção, pelo motivo das normas e orientações de distanciamento social continuarem em vigor diante da pandemia COVID-19 durante o ano letivo de 2021, visto que, grande número de instituições de ensino permanecem funcionando seguindo as necessárias medidas sanitárias, com 50\% das crianças atendidas, ou seja, as escolas e CREI's com suas atividades não presenciais alternadas com as presenciais; ou somente atividades remotas desde janeiro de 2021, no caso da Educação Infantil Pública Municipal de João Pessoa, o atendimento educacional está estruturado da seguinte forma: uma semana participam um grupo de crianças de forma presencial, enquanto o outro grupo fica em casa e são atendidos de forma virtual; na outra semana o grupo que estava em casa é atendido presencial e vice-versa.

Diante do exposto, dividimos a entrevista em duas etapas, conforme as temáticas:

a) A primeira parte da entrevista compreendeu as temáticas relacionadas aos fatores sociodemográficos: formação dos/as docentes, a faixa etária e o vínculo empregatício; 
b) A segunda parte da entrevista compreendeu quatro (4) temáticas afirmativas representadas pelas sequências de um (1) a quatro (4). Essas afirmativas estão representadas pela letra $R$, que diz respeito as respostas dos sujeitos da pesquisa, quando indagadas sobre as duas questões: A que está relacionado os desafios de tornar-se professor/a? Como adquirimos a profissionalidade docente? Conforme quadro 01 que se segue:

Quadro 1 - Afirmativas sobre a profissionalidade docente

\begin{tabular}{|c|l|}
\hline Nomenclatura & \multicolumn{1}{c|}{ Descrição } \\
\hline R 1 & Os desafios ao torna-se professor/a na Educação Infantil está relacionado a formação \\
\hline R 2 & Adquirimos a profissionalidade docente, através das experiências, estudos e pesquisas \\
\hline R 3 & $\begin{array}{l}\text { Os desafios de tornar-se professor é elaborar e construir sentidos de cada situação na } \\
\text { atuação docente }\end{array}$ \\
\hline R 4 & A profissionalidade docente é a busca constante sobre o fazer pedagógico. \\
\hline
\end{tabular}

Fonte: Elaborado pelas autoras

\section{Procedimentos estatísticos da análise dos dados}

Em conformidade com os objetivos propostos, os dados foram dispostos a dois tipos de análises estatísticas: descritivas, e variáveis, com o objetivo de avaliar se as variáveis formação, faixa etária e vínculo empregatício, repercutem de alguma forma na questão da profissionalidade docente na primeira etapa da Educação Básica.

\section{Resultados}

\section{Caracterização da amostra}

Esta parte da coleta de dados identificou as características gerais dos/as professores/as e foi composto por questões que versavam sobre a formação, faixa etária e vínculo empregatício dos/as sujeitos da investigação. Desse modo, observa-se que a pesquisa obteve um total de 20 respostas em sua maioria por sujeitos com faixa etária que compreende pessoas de 20 a 50 anos, bem como apresenta maior número de professoras com vínculo empregatício de prestação de serviço, conforme demonstrado nos dois gráficos que seguem: 
Gráfico 1 - Faixa etária Gráfico 02 - Vínculo empregatício
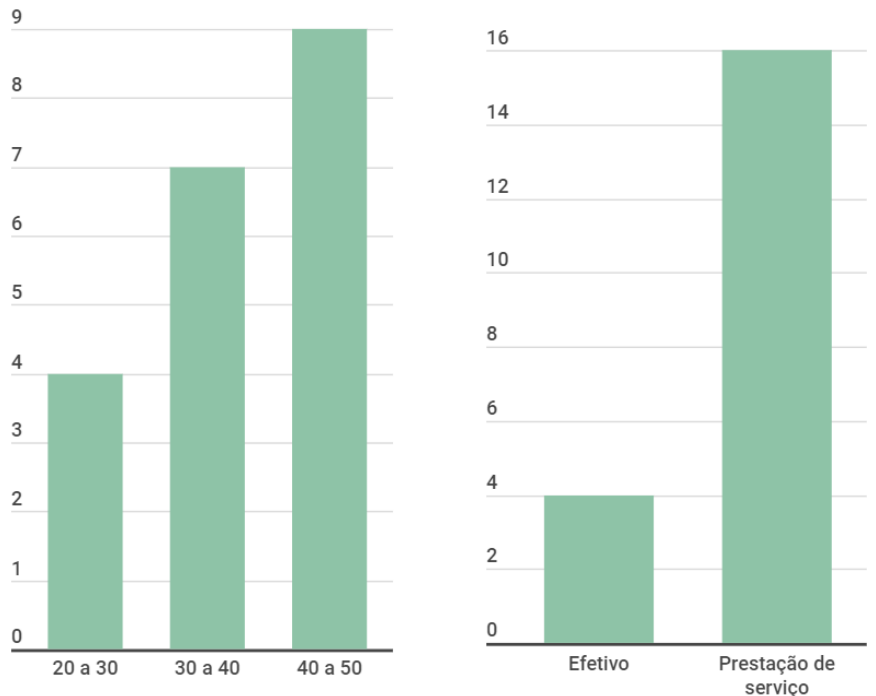

Fonte: Elaborado pelas autoras

\section{Estatísticas descritivas}

Ao analisar as estatísticas descritivas no que tange às mensagens dos/as docentes da Educação Infantil sobre a profissionalidade oriunda de suas experiências e formação, observase que os sujeitos se sentem satisfeitos com o curso inicial para a profissão docente, a graduação, embora alguns desejem cursar uma Pós-graduação e por algum motivo encontram obstáculos, que seja pela ausência de tempo disponível, pelas condições econômicas ou poucas vagas ofertadas. Conforme evidenciado no gráfico 02 que segue:

\section{Gráfico 2 - Formação}

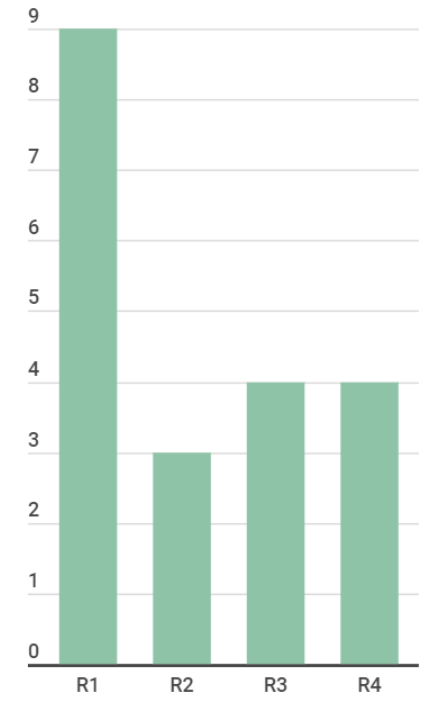

Fonte: Elaborado pelas autoras

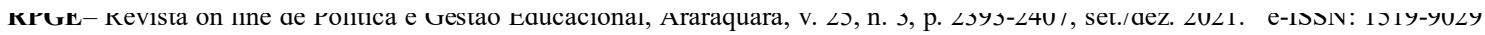


Analisando de maneira individual a percepção dos/as professor/a, evidencia-se que estes/as se sentem estimulados/as pela sua Instituição de Ensino Superior, ao mesmo tempo que têm suas expectativas não correspondidas, em relação ao acesso na pós-graduação para buscar maior profissionalidade.

Ao se analisar a afirmativa R1, verifica-se que nove docentes demonstraram uma maior satisfação quando indagados/a sobre sua formação profissional inicial e que os desafios ao torna-se professor/a na Educação Infantil está relacionado a formação continuada

Diante desse contexto, na afirmativa R2, três docentes demonstraram significância nas atividades laborais, foram os que apresentaram maior satisfação na atuação docente, que confirmaram a profissionalidade docente acontece através das experiências, estudos e pesquisas.

A afirmativa R3, tem-se que os desafios de tornar-se professor é elaborar e construir sentidos de cada situação na atuação. Assim quatro docentes confirmaram esses desafios de tornar-se professor/a para atuar na Educação Infantil.

Nessa direção, com base na afirmativa R4, quatro professores/as demonstraram satisfação na vertente de que a profissionalidade docente é a busca constante sobre o fazer pedagógico.

\section{Considerações finais}

Esta investigação objetivou compreender os desafios ao tornar-se professor, a partir de uma análise da profissionalidade docente na educação infantil na Rede Pública Municipal de Ensino de João Pessoa-PB. Diante desse objetivo central supracitado da pesquisa, buscou-se descobrir novos conhecimentos relacionados ao domínio científico. Desse modo, analisamos esse fenômeno por meio do enfoque fenomenológico como estratégia de investigação, que forneceu subsídio para compreender o objeto de estudo em sua realidade concreta. Assim, constatamos que a profissionalidade docente se constitui ao longo da trajetória de vida profissional e pessoal, a partir de saberes provenientes do conhecimento de mundo, da realidade social e cultural.

Nessa direção, parece mais coerente apontar a construção da profissionalidade dos professores/as, a partir da constatação de que pode haver incertezas que envolve a práxis, mas o que não muda é a criança que continua a ser a principal razão da escola e que precisa ter o seu desenvolvimento integral garantido. Assim, a instituição educativa e a profissão 
desenvolve-se em um contexto de mudança e evolução que repercute numa forma eficiente e eficaz da atuação docente.

Espera-se que as conclusões a partir da realização dessa pesquisa, possam em última instância, servir para clarificar a respeito da construção de uma profissionalidade significante, que tenha reflexos positivos na atuação docente que atuam na primeira etapa da Educação Básica, e consequentemente favoreça o desenvolvimento global do educando, sem que o docente perca de vista a concepção de criança sujeitos de direitos que aprende a ler, escrever e a se relacionar através das interações e brincadeiras.

Assim, esta investigação serviu para instigar a busca pela profissionalidade na perspectiva de torna-se professor/a para atuar nessa etapa da educação, contudo, esperamos que desperte interesse em outros pesquisadores no aprofundamento desse objeto de investigação, bem como sirva para a reflexão dos IES em oportunizar aos professores/as a oferta de matrículas em cursos de pós-graduação em educação, facilitando o retorno desses profissionais egressos da graduação, a academia e consequentemente contribuindo para a construção de uma permanente profissionalidade docente.

\section{REFERÊNCIAS}

BARBOSA, M. C. S. Culturas infantis: contribuições e reflexões. Rev. Diálogo Educ., Curitiba, v. 14, n. 43, p. 645-667, set./dez. 2014. Disponível em:

https://periodicos.pucpr.br/index.php/dialogoeducacional/article/view/1870. Acesso em: 07 out. 2021.

BARDIN, L. Análise de conteúdo. São Paulo: Edições 70, 1977.

BRASIL. [Constituição (1988)]. Constituição da República Federativa do Brasil de 1988. Brasília, DF: Presidência da República, [2016]. Disponível em: http://www.planalto.gov.br/ ccivil_03/constituição/constituicaocompilado.htm. Acesso em: 26 jul. 2021.

BRASIL. Lei n. 9.394, de 20 de dezembro de 1996. Lei de Diretrizes e Bases da Educação Nacional - LDB. Brasília, DF: Senado Federal, 1996. Disponível em: http:/www.planalto.gov .br/ccivil_03/Leis/L9394.htm. Acesso em: 27 jul. 2021.

BRASIL. Diretrizes Curriculares Nacionais para a Educação Infantil (DCNEI). Brasília, DF: Ministério da Educação/ Secretaria da Educação Básica, 2010.

BRASIL. Ministério da Educação e Cultura. Governo Federal. Base Nacional Comum Curricular: BNCC: Educação Infantil. Brasília, DF: MEC, 2017.

BRASIL. Ministério da Educação e Cultura. Governo Federal. Base Nacional Comum para a Formação Inicial de Professores da Educação Básica: BNC-Formação. Brasília, DF: MEC, 2019.

RPGE- Revista on line de Política e Gestão Educacional, Araraquara, v. 25, n. 3, p. 2393-2407, set./dez. 2021. e-ISSN: 1519-9029 
FREIRE, P. Pedagogia da Autonomia: saberes necessários à prática educativa. 46. ed. Rio de Janeiro: Paz e Terra,2013.

GATTI, A. B. et al. Para uma política nacional de formação de professores. São Paulo: Editora UNESP, 2013.

IMBERNÓN, F. Formação docente e profissional: formar-se para a mudança e a incerteza. São Paulo: Cortez, 2011.

KOHAN, W. O. Filosofia para crianças. 2. ed. Rio de Janeiro: Lamparina, 2008.

KRAMER, S. As crianças de 0 a 6 anos nas políticas educacionais no Brasil: educação infantil e/e fundamental. Educação \& Sociedade, Campinas, v. 27, n. 6, p. 797-818, 2006.

MINAYO, M. C. S. Pesquisa social: teoria, método e criatividade. Petrópolis, RJ: Vozes, 1994.

MOREIRA, D. A. O método fenomenológico na pesquisa. São Paulo: Pioneira Thonson, 2002.

NÓVOA, A. Os professores e sua formação. Lisboa: Dom Quixote, 1995.

RAMALHO, B. L; NUÑEZ, I. B.; GAUTHIER, C. Formar o Professor, profissionalizar o ensino: perspectivas e desafios. Porto Alegre, RS: Sulina, 2004.

SARMENTO, M. J. As culturas da infância nas encruzilhadas da $\mathbf{2}^{\mathbf{a}}$ modernidade. Braga: Instituto de Estudos da Criança / Universidade do Minho, 2003.

\section{Como referenciar este artigo}

PALHANO, T. R.; CORREIA, L. A.; NEVES, E. O. Os desafios ao tornar-se professor/a: uma análise da profissionalidade docente na educação infantil. Revista on line de Política e Gestão Educacional, Araraquara, v. 25, n. 3, p. 2393-2407, set./dez. 2021. e-ISSN:15199029. DOI: https://doi.org/10.22633/rpge.v25i3.15399

Submetido em: 11/09/2021

Revisões requeridas em: 15/10/2021

Aprovado em: 13/11/2021

Publicado em: 08/12/2021 